\title{
COMPORTAMENTOS AUTODESTRUTIVOS, SUBPRODUTOS DA PÓS-MODERNIDADE?
}

\author{
Self-destructive behaviors, postmodernity byproducts?
}

\author{
Liza Fensterseifer ${ }^{1}$ \\ Blanca Susana Guevara Werlang²
}

\section{Resumo}

O presente artigo aborda, por meio de uma exposição teórica, o quanto a forma de vida pós-moderna pode propiciar, ainda mais, a exacerbação de um sentimento de vazio e desesperança no homem contemporâneo, contribuindo para o aumento nas taxas de comportamentos desviantes e patológicos, como os voltados à autodestruição. Para isso, apresenta-se brevemente a idéia e o conceito de pós-modernidade, momento histórico e cultural que se vive hoje, caracterizado, dentre outras coisas, pelo sentimento de desamparo, perda de identidade e exacerbação do narcisismo, demarcando a influência disso nas formas de subjetivação do ser humano inserido neste contexto. A elevada incidência de psicopatologias, tais como a depressão, os quadros narcisistas e borderline, o uso e abuso de drogas e os transtornos de ansiedade, assim como atos violentos auto e hetero-infligidos, apontam para sintomas típicos do mundo pós-moderno. Discute-se também até que ponto a sociedade contemporânea pode ser responsabilizada por estas manifestações, no momento em que tantos comportamentos desviantes, e inclui-se aqui os atos terroristas, a corrupção, os índices de suicídio, a busca por alívio e satisfação com de substâncias químicas, são tão freqüentes atualmente como nos tempos passados. Serão estes os subprodutos da pós-modernidade? Destaca-se, ainda, o lugar e o papel da Psicologia neste contexto, no sentido de mostrar o seu compromisso com a promoção da saúde e do bem-estar dos indivíduos.

Palavras-chave: Pós-modernidade; Psicopatologias; Comportamentos autodestrutivos; Subprodutos; Psicologia.

1 Psicóloga Clínica. Mestre em Psicologia Clínica pelo Programa de Pós-Graduação em Psicologia da PUCRS. Doutoranda do Programa de Pós-Graduação em Psicologia da PUCRS. Professora Assistente do Instituto de Psicologia da Pontifícia Universidade Católica de Minas Gerais - PUC-MG, Endereço para contato: Rua Júlio Diniz, 257, ap. 205, Bairro Santa Branca, Belo Horizonte, MG, Brasil, CEP: 31565-180, E-mail: pxl@terra.com.br

2 Psicóloga Clínica. Especialista em Diagnóstico Psicológico. Doutora em Ciências Médicas - Saúde Mental - UNICAMP. Professora Adjunta do Programa de Pós-Graduação em Psicologia da Faculdade de Psicologia da Pontifícia Universidade Católica do Rio Grande do Sul - PUCRS, Endereço para contato: Av. Ipiranga, 6681 Prédio 11 - 9o andar sala 924 PUCRS, CEP 90619-900 - Caixa Postal 1429 - Porto Alegre, RS, Brasil, E-mail: bwerlang@pucrs.br 


\section{Abstract}

This article discusses, within a theoretical approach, how postmodern lifestyle can exacerbate loneliness and hopelessness feelings in contemporary man, contributing to increase rates of deviant and pathological behaviors, such as self-destruction. The paper briefly presents the idea and concept of postmodernity, the historical and cultural moment we currently live, characterized by feelings of helplessness, lost of identity and exacerbation of narcissism, outlining their influence on the subjectivation of the human being within this context. The high incidence of psychopathologies such as depression, narcissism and borderline narcissistic make-ups, drug use and abuse and anxiety disorders, as well as violent acts - self-inflicted or not - indicate typical symptoms of the postmodern world. It is also discussed whether contemporary society could be considered responsible for these manifestations, as deviant behaviors such as terrorism, corruption, suicide and the search for relief and satisfaction through chemicals are as frequent as they were in the past. Would they be postmodernity byproducts?The role of Psychology within this context is also highlighted, intending to show its commitment to promote individuals' health and wellbeing.

Keywords: Postmodernity; Psychopathologies; Self-destructive behaviors; Byproducts; Psychology.

\section{Introdução}

Não é difícil perceber como a violência está presente na vida das pessoas. E faz-se referência aqui a todas as formas de violência, usando a palavra em seu sentido amplo. Pode-se pensar o quanto se é violentado por um tempo que passa depressa demais, arrebatando todo o "tempo" que se tem; o quanto se é violentado pela cultura do belo, pelo imperativo do prazer, pela solidão que vem da superficialidade das relações, enfim, por algumas das coisas que têm sido chamadas de características do pós-moderno. Neste sentido, Harvey (2004) aponta justamente a heterogeneidade, a fragmentação, a descontinuidade, o efêmero, a indeterminação, a indiferença e a desconfiança nos discursos universais como marcos importantes do pensamento pós-moderno.

No seu artigo "Mal-estar na civilização", publicado em 1929, Freud (1974) já apresentava sua preocupação com o estatuto do sujeito no mundo moderno, circunscrevendo-o a um mal-estar típico da modernidade. É como se já soubesse da angústia moderna a que os sujeitos estão submetidos hoje, e da qual fala Souza (2000), ao destacar a solidão que demarca a vida do homem pós-moderno. Birman (2003) acredita que o que se "perdeu" na passagem da modernidade para a pós-modemidade é algo, sem dúvida, da ordem do desejo do sujeito, que "não consegue mais acreditar, como anteriormente, que pode transformar a si mesmo e ao mundo com seu desejo, de maneira a poder reinventar a si mesmo e a ordem social” (p. 82). Assim, a crença em uma possibilidade de reinvenção é que foi perdida, impossibilitando o homem de hoje a crer em seu poder de mudar. Por tudo isso é que o pós- moderno demarca uma cultura do narcisismo, do ser só e de transformar apenas a própria existência em uma finalidade fundamental da vida.

Quando Souza (2000) usa a palavra mônada para se referir aos indivíduos da cultura capitalista e pós-industrial, leia-se, pós-moderna, é possível pensar que ele o faz justamente motivado pela idéia do encapsulamento em si mesmo, em princípio, tão comum nos dias de hoje. Basta pensar na grande incidência das patologias ditas do "vazio", como a depressão, os quadros narcisistas e borderline. Enfim, será que é possível sobreviver a essas mudanças, que demarcam uma nova cartografia do funcionamento da vida?

Parece possível pensar que sim, mas certamente com um alto preço, que não se sabe ainda se a sociedade realmente está disposta a pagar. A depressão (apontada por muitos como o mal ou a doença do século passado), o uso e abuso de drogas, a violência auto e hetero-infligida são sintomas típicos do mundo pós-moderno. Segundo Sisto (2003), a ocorrência prognosticada de catástrofes naturais, a manutenção de guerras intermináveis, o terrorismo político/religioso anunciam um possível retorno a um estágio primitivo de sociedade, sem normas, sem limites, sem justiça, afastando-se profundamente do ideal de um mundo seguro. A sociedade atual, para esta autora, encontra-se ameaçada pelo medo das ações de violência auto-infligida (comportamento suicida), interpessoal (familiar, do casal, comunitária) e coletiva (social, política, econômica, religiosa), pela falta de expectativas das novas gerações, pelos ambiciosos objetivos de desenvolvimento, pela terrível e constante falta de afeto, ausência de vida amorosa, falta de apego e respeito ao próximo. 
Assim, constata-se altíssimo consumo de medicamentos (calmantes, relaxantes, sedativos...), ações alarmantes de tráfico de drogas, atos de injustiça e corrupção, mortes violentas acontecidas por acidentes graves (meios de transporte), por agressões fatais e por suicídios, que explicitam e tornam flagrante a realidade em que se vive. Especificamente sobre o comportamento suicida, os dados epidemiológicos nacionais e internacionais (Barros, Oliveira \& Marín-León, 2004; Bertolote \& Fleischnann, 2004a, 2004b) apontam que em sujeitos com idade entre 15 e 34 anos, o suicídio figura como um importante e incidente acontecimento, que tem preocupado autoridades, sendo considerado uma questão de saúde pública. Então, o que se propõe abordar, por meio de uma exposição teórica, no presente artigo, é o quanto a forma de vida pós-moderna pode propiciar a exacerbação de um sentimento de vazio e desesperança, contribuindo para o aumento nas taxas de comportamentos desviantes e patológicos, como os voltados à autodestruição. Para isso, fez-se uma breve explanação a respeito do que é compreendido como pós-modernidade, as conseqüências, em termos psíquicos, desta na constituição do sujeito e, enfim, o lugar e o papel de comportamentos patológicos neste contexto.

\section{Mas, afinal, o que é a pós-moderni- dade?}

Para Bauman (1999), a idéia da pós-modernidade representa algo que se determina e define pelo fato de ser 'pós', posterior, e esmagada pela consciência dessa condição. Destaca igualmente que não há, necessariamente, rejeição às idéias da modernidade, e sim, uma reflexão sobre elas, o que propiciou a percepção da necessidade de uma mudança. Assim, a pós-modernidade é, para este autor, a "modernidade que atinge a maioridade, a modernidade olhando-se a distância, e não de dentro, fazendo um inventário completo de ganhos e perdas, psicanalisando-se, descobrindo as intenções que jamais explicitara, descobrindo que elas são mutuamente incongruentes e se cancelam" (p. 288).

Por outro lado, Santos (2001) sustenta que o nome pós-modernidade não é adequado, uma vez que ela demarca uma fase de transição, que se apresenta superficialmente como um grande va- zio, uma crise. A relação do moderno e do pósmoderno é contraditória, sendo, em alguns momentos, de ruptura, e em outros, de continuidade. Esta idéia é parcialmente compartilhada por Harvey (2004), quando aponta que há mais continuidade do que diferença ou ruptura entre a história do modernismo e do pós-modernismo.

Muitos autores apontam características responsáveis pelas feições desse período. Para Lourenço (2004), foi a indecisão a respeito da essência do homem e da verdade que produziu reflexos nos comportamentos do homem contemporâneo, que se concretizam na efemeridade dos relacionamentos, em tantas formas de violência, no consumismo, no narcisismo exagerado. Conforme Santos (2001), outra importante característica da pós-modernidade é a rapidez e a intensidade com que as coisas acontecem, o que, assim como torna a realidade "hiper-real", também a banaliza e a torna trivial, o que diminui sua capacidade de entusiasmar, surpreender e empolgar os indivíduos. As relações são desterritorializadas, ultrapassando fronteiras policiadas pelos idiomas, pelos costumes, pelas tradições, pelas ideologias. O autor aponta a utopia como única solução para enfrentar a mudança paradigmática proposta pela pós-modernidade, uma vez que é a partir dela que novas possibilidades e vontades humanas são exploradas. É necessário que o futuro possa ser reinventado e que um novo horizonte de alternativas possa ser vislumbrado. $\mathrm{O}$ status adquirido pela ciência na modernidade, com a extrema valorização da razão, fez com que o pensamento utópico fosse praticamente esquecido. E, será que a morte da utopia não é, também, a morte do futuro? Para Santos (2001), a utopia funciona como a esperança, pois é por meio dela que o indivíduo recusa 0 fechamento das possibilidades, cria novas alternativas e, principalmente, a vontade de lutar por elas.

No entanto, o que parece de mais importante e contundente em relação a este momento, que tem sido (adequadamente ou não) denominado de pós-modernidade, é o impacto que suas características têm causado nos sujeitos e em seu modo de viver. À medida que a rejeição das pluralidades e diferenças se intensificou, a solidão passou de um sentimento esporádico para uma condição padrão. Cabe lembrar que os horrores cometidos contra os judeus, durante a Segunda Guerra, deflagram a intolerância com que era tratado aquele que fosse considerado diferente. Neste con- 
texto, a solidão era algo a que o sujeito deveria se ajustar. Bauman (1999), fundamentando-se em Wasserman, descreve muito bem o sentimento de não pertencença e de solidão, fruto das novas cartografias da pós-modernidade, quando refere que ninguém mais considera o outro seu afim, e que hoje, a grande incerteza não diz respeito a qual grupo eu pertenço, e sim à dúvida de realmente pertencer a algum.

A pós-modemidade iluminou o fato de que o mundo é regido pela incerteza, e não mais pela certeza e pela existência de uma verdade única, como prometia a ciência, e fez com que o homem tomasse consciência disso. Então, parece possível dizer segundo Bauman (1999), que o desconforto causado pela certeza de que não há saída nem solução para a incerteza que pauta e ordena a vida é a fonte de mal-estares típicos e específicos.

A grande incerteza frente às coisas, marca registrada da pós-modernidade, advém da superação do estatuto da ciência como algo onipotente, onipresente e onisciente. No século passado, por exemplo, a aposta foi muito alta na crença de que a ciência progrediria a ponto de poder dominar cada vez mais a natureza e, sem dúvida, todos os avanços contribuíram em grande parte nessa direção, por constantes desafios aos limites do conhecimento, principalmente no que diz respeito ao aumento da duração média de vida. Nesse contexto, em que o mundo volta-se para o progresso e para a produtividade, as mortes não naturais, as banais e, principalmente, as por suicídio, irrompem como uma afronta, estabelecendo um paradoxo, um contra-senso. Neste sentido, a pósmodernidade deflagra o fato de que a ciência, por tudo o que se sabe e o que se pode saber, é apenas uma versão dentre muitas. Logo, passa a ser na pluralidade e não na sobrevivência dos mais aptos que reside a esperança.

O pesadelo do homem contemporâneo é, então, para os teóricos da pós-modemidade, ficar sozinho, alienado, à deriva, sem raízes. A maior cicatriz emocional deixada pela pós-modernidade foi o temor do vazio, representado pela falta daquele padrão inequívoco, obrigatório e universal. Além disso, numa sociedade que prioriza 0 consumo, o fracasso gera culpa e vergonha, a frustração alimenta o embaraço e a apatia, fato que, conseqüentemente, gera manifestações importantes, e por que não pensar, inevitáveis, na vida e nas formas de subjetivação dos indivíduos.

\section{Conseqüências inevitáveis da contem- poraneidade}

A sociedade pós-moderna ameaça o eu dos indivíduos com a desintegração, uma vez que o sentimento de vazio é uma constância. Lasch (1990) fala de uma cultura do narcisismo, justamente para pontuar as estratégias de sobrevivência que tiveram de ser adotadas: apatia seletiva, descompromisso emocional frente aos outros. Além disso, destaca a necessidade de os indivíduos, em sua vida cotidiana, assumirem características bastante indesejáveis, típicas dos comportamentos adotados em situações extremas. O mesmo autor cita Victor Frankl, que salientou muito o assalto cometido ao significado, uma vez que é característica da sociedade moderna frustrar as buscas pelo significado das coisas e, em última instância, da vida. A automação nas indústrias e empresas privou os sujeitos de um trabalho útil, gerando o tédio e a insatisfação. O advento da ciência e da cientificidade fez ruir a crença na religião. Tudo isso parece ter criado um vazio existencial, uma falta de significado para a existência dos homens, que quando ficam privados de significado, sua vontade de viver e de sobreviver ficam ameaçadas.

Cada época ou momento histórico tem formas particulares e específicas de patologias, que, de certa forma, expressam de maneira exacerbada uma estrutura de caráter subjacente. Isso fica bastante claro quando se pensa que a histeria e as neuroses obsessivas, patologias típicas e freqüentes na época de Freud, representavam a sociedade daquele tempo, que vivia uma fase prematura da ordem capitalista, marcada pela avidez, pelo fervor e devoção fanática pelo trabalho e, o principal, uma repressão feroz da sexualidade (Macedo, 2003).

Não parece que a própria pós-modernidade seja responsável pelo mal-estar que o homem vem sentindo e no qual vem vivendo, mas sim, os efeitos dela sobre a subjetividade. Na atividade clínica é possível observar as demandas que esses efeitos vêm gerando, tornando as pessoas queixosas, insatisfeitas, vazias, desesperançosas, desmotivadas, agressivas, impulsivas. Além disso, elas têm dificuldade para entrar em contato com seus sentimentos, uma vez que parece mais fácil e, com certeza, menos doloroso, buscar em práticas alienantes formas de não enfrentar ou não ter que se deparar com suas próprias dores e feridas. 
A cultura do narcisismo estabelece justamente a idéia de que eu me basto, precisando do outro apenas para, eventualmente, gratificar-me e satisfazer-me. Então, as relações são pautadas na superficialidade, na rapidez, na avidez, logo, no vazio. Até porque, a sociedade exige a competição, que eu vença e seja melhor que o outro, que eu tenha mais do que o outro, o que empobrece e acaba matando a capacidade do indivíduo de investir no outro. $O$ sujeito pós-moderno preocupase menos em ser amado, e mais em ser admirado.

Parece que na contemporaneidade, espera-se que as pessoas construam e projetem sua identidade a partir do princípio imediato da obsolescência, o que faz com que possam descartar identidades antigas e adotar novas como quem troca de roupa. Ao mesmo tempo em que esta plasticidade pode ser fascinante, pode ser extremamente desestruturante, uma vez que tudo acontece apenas no plano do imediato, tudo é mutante e mutável, desconcertante. O eixo da estratégia da vida pós-moderna é, justamente, evitar que determinada identidade se fixe. É preciso saber ser plástico, versátil, tipo camaleão. Isso exige, de homens e mulheres pós-modernos, que cada dia da vida seja vivido de cada vez, sem fixar-se em nada, sem comprometer-se ou compromissar-se com nada, nem com ninguém (Bauman, 1998). Parece que isso significa, conseqüentemente, viver e estar só, vazio. Dar conta desses sentimentos é tarefa do indivíduo, que acaba, muitas vezes, refugiando-se em "barricadas" pouco seguras.

\section{A busca de um refúgio: o papel das psicopatologias}

Na atualidade, o autocentramento do sujeito atingiu limiares impensáveis, apresentandose pela exagerada estetização da existência, onde a exaltação do próprio eu é o que mais importa cultura do narcisismo. Aqui, o valor de cada sujeito é atribuído de acordo com a sua aparência, instituindo-se, assim, a hegemonia da aparência, que passa a ser o critério fundamental do ser e de sua existência, conforme Birman (2003). Vive-se, então, como assinalou Debord (1997), na sociedade do espetáculo, em que a exibição é o lema e a razão da existência dos homens.

E como se situa a psicopatologia neste contexto? O que está em pauta no funcionamento psíquico do sujeito da contemporaneidade é a necessidade de glorificar o eu e sua existência, e todos aqueles que, por algum motivo, fracassam nesta empreitada, sofrem. A manifestação deste sofrimento caracteriza as patologias atuais, e elas concentram-se mais fortemente no que chamamos de depressões, síndrome do pânico e dependências químicas (toxicomanias), de acordo com Birman (2003). Numa cultura que exalta desmesuradamente $0 \mathrm{eu}$, os deprimidos e as pessoas que sofrem com o pânico, não têm vez nem lugar, pois estão impossibilitados de serem personagens e cidadãos da sociedade do espetáculo. Os toxicômanos entram neste contexto na medida em que por meio das drogas é que buscam alcançar o elan necessário para a inserção na sociedade da atualidade. 0 estado de inebriamento tóxico, proporcionado pelo uso e abuso de substância psicoativas, proporciona aos indivíduos, nem que seja apenas por uma fração de segundo ou por um tempo limitado, a sensação de não mais estar de fora da cultura que tem no narcisismo o seu maior ícone. A droga oferece uma promessa de não-confronto com o desamparo, sentimento típico da pós-modemidade. Na verdade, a busca desesperada do sujeito é de proteção face ao desamparo, de um mundo que possibilite sua proteção frente ao medo do indeterminado e do acaso. As condutas violentas e autodestrutivas podem ser entendidas, também, como formas de deter o fluxo de desprazer, de sofrimento e de desconforto que circula no psiquismo do homem pósmoderno. Vilhena e Maia (2002) destacam que a cultura do narcisismo corresponde à exacerbação da violência, uma vez que os mecanismos narcísicos de relação com o outro potencializam os sentimentos de impotência e desamparo.

Vivemos, hoje, em uma sociedade que apregoa a liberdade individual, e que estimula a busca constante de prazer, o que, freqüentemente, acaba gerando experiências de fracasso e insuficiências. Dessa forma, é possível pensar que as manifestações de sofrimento psíquico, no momento atual, são mais motivadas pela exigência do prazer do que por sua restrição (Garcia \& Coutinho, 2004). O homem contemporâneo caracteriza-se pelas experiências de desenraizamento, de errância, vinculadas a perdas de referências simbólicas. E isso se traduz em um sofrimento psíquico que denuncia a insegurança e, principalmente, a instabilidade identitária, e que pode ser chamado de desamparo. Quem está desamparado está à mercê. 
As patologias da ansiedade, principalmente o transtorno de pânico, ilustram a ênfase na exterioridade, sendo um fiel representante do modus vivendi que caracteriza a sociedade contemporânea, afirmando, incontestavelmente, a dor do existir na pós-modernidade. A depressão, ao contrário, manifesta o lado sombrio da contemporaneidade, configurando-se como sua herdeira legítima, representando uma resistência silenciosa no cenário pós-moderno.

Sobre a agressividade, Freud (1994a), em seu artigo "Além do princípio do prazer", de 1920, já apontava a existência de duas forças opostas no homem: amor e ódio. Além disso, parece importante lembrar que, pouco depois da Primeira Guerra Mundial, este autor reconhecia (na construção de sua teoria) a existência da agressão e da destrutividade nos seres humanos, introduzindo um novo dualismo pulsional: pulsão de vida/pulsão de morte. Os acontecimentos durante os anos de 1914 a 1918, descritos por Gay (1989) como "o grande morticídio", trouxeram a Freud revelações sobre o que postulou como selvageria humana, levando-o a atribuir um papel de destaque à agressão. De lá para cá estas explicações não se modificaram muito. Então, que mecanismos atuam na sociedade contemporânea, ou não atuam, para que o homem não tenha conseguido renunciar às suas pulsões agressivas, ou sublimá-las? Lourenço (2002) destaca que a inibição da agressividade só se efetiva com promessas de felicidade e proteção, e que é justamente isso que está falido na civilização de hoje, comprometendo os limites dos impulsos de destruição. Assim, a agressividade e a violência, e suas tantas manifestações, entram neste contexto como mais um sintoma característico do momento atual em que vive o homem de hoje. Os transtornos de conduta, os transtomos de personalidade anti-social, a autodestruição, descrita por Shneidman (1993, 1994, 1999, 2004) como uma fuga de uma situação de dor psicológica insuportável, um protesto contra o desespero e o sofrimento, demarcam, novamente, o quanto o sentimento de desamparo causado pela pós-modernidade pode fomentar a incidência de determinadas psicopatologias.

\section{Autodestruição como outra solução}

$\mathrm{Na}$ atualidade, o sujeito perdeu a crença de que, pelo desejo, poderia reinventar-se e rein- ventar o mundo. As culturas do narcisismo e do espetáculo consolidam-se a partir de um modelo que cala esta possibilidade. $\mathrm{O}$ que caracteriza a subjetividade do homem pós-moderno é a impossibilidade de perceber e admirar o outro, uma vez que se vive tão autocentrado, pensando sempre apenas no próprio umbigo, que nada além de um palmo do nariz pode ser enxergado. E é neste cenário que se instaura a violência, assumindo as mais diversas formas de manifestação.

O desamparo sentido pelos indivíduos é um dos frutos da morte das utopias, aumentando o desespero e a busca frenética das pessoas por estratégias que aliviem suas individualidades. A idéia freudiana de que a felicidade jamais poderia ser alcançada por uma fórmula universal, sendo uma tarefa individual e singular, possibilitada pela economia psíquica e pulsional de cada sujeito, é o oposto do preconizado pelo discurso iluminista da ciência, que prometeu o bem-estar para todos. Segundo Birman (2003), o desamparo é o grande responsável pela instauração do mal-estar típico da pós-modernidade.

O suicídio ou as condutas autodestrutivas em geral inserem-se aqui como uma saída possível para este sentimento, do qual fala Birman (2003). Estes comportamentos têm grande impacto e são, sem dúvida, soluções definitivas para problemas temporários, e o que tem se observado é que cada vez mais as pessoas têm, efetivamente, cogitado no suicídio como uma alternativa para dar fim à sua dor. No entanto, a preocupação frente a esta forma de manejar as dificuldades referese, também, às repercussões do ato suicida, uma vez que, segundo Kalina e Kovadloff (1983), quando um sujeito comete o suicídio, morre com ele a proposta de um grupo, de uma comunidade. A comunidade a que pertence o suicida passa a viver com o significado deste ato. Logo, isso denuncia o fato de que existe uma profunda correlação entre a pessoa que se mata, a família dessa pessoa e, conseqüentemente, a sociedade da qual faz ou fazia parte. O suicídio pode ser compreendido, então, como a conseqüência de um profundo debilitamento da auto-estima do indivíduo, e no momento em que a sociedade contribui para 0 sentimento crescente de despersonificação de seus integrantes, é possível pensar que ela fomenta e prolifera patologias suicidas ou autodestrutivas, tais como toda a gama de comportamentos de risco (dirigir alcoolizado, ter vida sexual promíscua...). 
Se o contemporâneo é marcado pelo predomínio do imperativo do prazer, o consumismo funciona como uma resposta social ao mal-estar próprio dos dias atuais, e assim como as toxicomanias, serve para silenciar a dor de se descobrir sem referências. O desejo e o prazer passam a ser a tônica do viver pós-moderno, constituindo-se como o novo ideal de felicidade e bem-estar, ou seja, é preciso ter, satisfazer-se, gratificar-se (Saraiva, 2002). Portanto, a pessoa que fracassa ou perde algo na vida, pode voltar seu potencial agressivo contra si mesmo, ação que demarca a completa dissolução da auto-estima do sujeito. O homem que se mata, busca a libertação de um sentimento profundo e intolerável de ausência, sendo a expressão mais radical de uma crise de despersonificação, uma vez que só é possível conceber o próprio fim quando o sujeito não se reconhece mais, identificando-se com o agressor introjetado. Freud (1994b), em seu artigo "Luto e melancolia”, de 1917, já fazia esta interpretação das condutas suicidas, atribuindo a elas o estatuto de ataque à pessoa amada que foi perdida, com quem o indivíduo havia se identificado. A melancolia faz com que 0 sujeito trate a si mesmo como objeto, direcionando para dentro a hostilidade que deveria ser projetada para o exterior, voltando contra si o impulso de destruição e morte. Como o ego está identificado com o objeto perdido, isto propicia que consinta a destruição de sua própria vida.

Esse despedaçamento da personalidade, a que se referem Kalina e Kovadloff (1983), é o cenário sobre o qual se perfilam as formas contemporâneas do progresso. Quando o suicídio acontece, ele denuncia o fracasso dos paliativos que tentam mascarar ou maquiar a impossibilidade de continuar vivendo e suportando o intenso vazio da sociedade e da vida pós-moderna. Justamente por isso é que os autores ressaltam que é ingênuo e totalmente equivocado pensar que 0 suicídio é o representante, apenas, de uma patologia individual, ou mesmo pensar que os indivíduos que aventam a possibilidade de se matar e aqueles que efetivamente consumam este pensamento são raridades ou focos isolados. A sociedade em que vivemos, pelo contrário, é ou está em profundo conflito, institucionalmente debilitada e com uma identidade cultural bastante difusa. Assim, nada mais resta aos que vivem nela, senão buscar saídas ou defesas para os sentimentos de desamparo e mal-estar que ela lhes causa.
A auto-agressão ou autodestruição possui os mais variados matizes, podendo traduzir-se no consumo abusivo de fumo, bebidas ou outras drogas, no trabalho sem limite, do tipo "workaholic", nos exageros alimentares, ou no ato letal de um disparo na própria cabeça, para citar apenas alguns. O suicídio é o pólo máximo da manifestação autodestrutiva, confirmando o "fracasso" da inserção do sujeito na vida, aceitando o seu não lugar na sociedade, literalmente desistindo (Cassorla, 2004).

Neste contexto, o maior esforço dos estudiosos que se ocupam das questões relacionadas à autodestruição é identificar fatores de risco ou variáveis preditoras deste evento. A depressão, a desesperança, o uso e o abuso de substâncias, tais como álcool e drogas, a presença de uma dor psicológica - em inglês, psychache - insuportável, caracterizada por Shneidman (1993, 1994, 1998, 1999, 2004, 2005) como emoções negativas que conduzem o indivíduo ao suicídio, são alguns dos elementos mais importantes elencados pela literatura. Na subjetividade do sujeito vive um mal-estar, uma dúvida profunda quanto ao verdadeiro valor e sentido de sua existência.

Para Macedo (2003), no momento em que a modernidade prometeu um lugar de primazia à razão, à racionalidade e à individualidade, o homem descuidou de sua subjetividade, afastandose da noção de alteridade como valor. Além disso, a subjetividade produzida na pós-modemidade tem seu centro no valor da exterioridade, assumindo uma configuração estetizante, em que o outro e o seu olhar passam a ocupar um papel de grande importância na economia e na organização psíquica do sujeito. Por isso é que tem se dito que existe uma cultura do narcisismo, que tem pautado as relações. As preocupações da pós-modernidade são com a superfície, e não com as raízes, com o significante, não com o significado, conforme Harvey (2004). E tudo isso tem uma grande conseqüência, uma vez que este retrato da pósmodernidade só se aplica e tem validade a partir de um determinado modo de pensar, experimentar, interpretar e ser no mundo. Isso quer dizer que a pós-modernidade também moldou o sujeito quanto à sua personalidade, sua motivação e seu comportamento.

Na sociedade em que se prioriza o consumo, o valor de cada um é avaliado de acordo com 0 que se tem a oferecer como produto, com 
o que se faz. Logo, a auto-estima do homem da atualidade fica totalmente subordinada ao êxito social. O sentimento do eu baseado na autoconfiança e nas convicções e crenças pessoais a respeito de seu próprio valor não mais existe. $O$ sentimento que a pessoa tem referente a si mesmo e à sua importância depende do eco que encontra, ou que não encontra, nos outros. Ninguém mais crê no seu valor, prescindindo de sua popularidade junto aos outros. Além disso, numa sociedade capitalista, a produção do indivíduo também pauta e delimita seu valor, e a instabilidade deste processo pode ser igualmente apontada como outra das causas decisivas da despersonificação e, em última instância, do suicídio contemporâneo.

Dessa forma, não há como este processo de depauperação e esvaziamento do eu não incidir na proliferação das patologias voltadas para a destruição. Por meio delas o indivíduo encontra um alívio, pois atua, sem rodeios ou escrúpulos de consciência, alguns de seus impulsos mais primitivos e, eventualmente, até psicóticos, tais como as toxicomanias, o furto, o assassinato do outro, o assassinato de si. Por isso, Kalina \& Kovadloff (1983) dão ao comportamento suicida idéia que se (re)atualiza na sociedade pós-moderna e no modelo cultural vigente, um status de traço distintivo central, e não periférico, uma vez que não é um lapso, não pertence à fronteira do processo civilizatório, e sim ao seu núcleo. Tanto as formas "disfarçadas" de suicídio, quanto o suicídio propriamente dito, são modos, mesmo que ilusórios, que o homem encontrou de contestar os efeitos desastrosos de sua inconsistência pessoal, importante legado da pós-modernidade.

\section{Considerações finais}

Ao passear pelo legado da pós-modemidade, fica evidente que o sujeito que vive este e neste momento histórico precisa adaptar-se. E esta adaptação não é simplesmente de ordem prática, mas sim de ordem funcional. $\mathrm{O}$ homem pós-modemo está vendo seu próprio funcionamento dar sinais de desgaste, de cansaço. Atrapalhadamente, maneiras de não sucumbir ao sentimento de vazio e desamparo são freneticamente buscadas, no afã de efetivamente encontrar o que todos falam que a pós-modemidade veio trazer: o prazer sem limite, o estético, o desejo, os espetáculos, enfim, a felicidade imestrita. O pro- blema foi que a corrida atrás deste sonho pós-moderno produziu alguns rejeitos: aqueles que fracassaram e não encontraram o prazer, o cenário belo, uma vida brilhante e espetacular.

Neste contexto é que se abre o espaço para a psicopatologia, para os distúrbios psíquicos, para as dores da alma. Depressão, dependência química, pânico, autodestruição, agressão, terrorismo, comupção: manifestações típicas e freqüentes dos dias atuais. A grande questão que se impõe é o quanto a sociedade pós-moderna é responsável pela produção de sujeitos psiquicamente doentes, tão descrentes e desesperançosos em relação à vida e ao futuro que percebem o suicídio ou outros comportamentos de risco que, indiretamente e inconscientemente levam o indivíduo, senão à morte, bem próximo dela, como saídas possíveis e, mais do que isso, prováveis.

A psicologia se insurge aí como uma possibilidade de atender às demandas da contemporaneidade, oferecendo um espaço para que o sujeito possa olhar para tudo isso e pensar em si, na sua dor, pautando sua existência em outros imperativos, que não os vigentes. No entanto, parece que também é marca registrada do homem pósmodern, o aprisionamento na impossibilidade de parar para pensar, fazendo um movimento de voltar-se para dentro, talvez com receio de olhar para si e se assustar com o que vai encontrar.

Realmente, o mundo tradicional já não existe mais, e o que está aí adquiriu novas feições e dimensões. O sentimento de desamparo e o potencial de incerteza do sujeito aumentam bastante, demarcando a necessidade deste de inscrever-se num mundo que, ao mesmo tempo em que lhe abre muitas possibilidades, aponta-lhe muitas impossibilidades existenciais. Então, não há nada a fazer? Há, e muito. Há que se fazer com que as pessoas possam redescobrir o valor de seu ser, desatrelado ao valor de seu ter. Há que se fazer com que aprendam que a dor e o sofrimento, em alguma medida, fazem crescer, e que não devem ser ferozmente combatidos. Há que se fazer com que a busca do prazer, o individualismo e o narcisismo retomem seus lugares na ordem do dia, deixando de ser os protagonistas da cena pós-moderna. Se isto é utopia, que seja. Se isso é utopia, se quer acreditar, assim como Santos (2001), que isso "não é tarefa fácil nem é uma tarefa individual. Mas se é verdade que a paciência dos conceitos é grande, a paciência da utopia é infinita” (p. 346). 
Para tanto, há que se pensar onde se insere a Psicologia neste cenário, com seu compromisso com a promoção da saúde, com a prevenção de quadros psicopatológicos, com a possibilidade de se repensar e, até mesmo, reinventar formas de viver numa sociedade forjada na descrença e na desesperança. Que novas formas de subjetividade foram produzidas pela nova ordem social em que se vive, não há como negar. No entanto, parece possível pensar que a Psicologia, como ciência do comportamento, pode lançar um outro olhar para a contemporaneidade, ocupando, assim, um importante papel na e para a sociedade.

\section{Referências}

Barros, M., Oliveira, H., \& Marin-León, L. (2004). Epidemiologia no Brasil. In: B. G. Werlang \& N. J. Botega. Comportamento Suicida (pp. 4558). Porto Alegre: Artmed.

Bauman, Z. (1998). 0 mal-estar da pós-modernidade. Rio de Janeiro: Jorge Zahar.

Bauman, Z. (1999). Modernidade e ambivalência. Rio de Janeiro: Jorge Zahar.

Bertolote, J. M \& Fleischmann, A. (2004a). Suicide and pychiatric diagnosis: A woldwide perspective. World Psychiatry, 1(3), 181-185.

Bertolote, J. M, \& Fleischmann, A. (2004b). Suicídio e doença mental: Uma perspectiva global. In: B. G. Werlang \& N. J. Botega. Comportamento Suicida (pp. 35-44). Porto Alegre: Artmed.

Birman, J. (2003). Mal-estar na atualidade: A psicanálise e as novas formas de subjetivação. Rio de Janeiro: Civilização Brasileira.

Cassorla, R. M. S. (2004). Suicídio e autodestruição humana. In: B. G. Werlang \& N. J. Botega. Comportamento Suicida (pp. 21-33). Porto Alegre: Artmed.

Debord, G. (1997). A sociedade do espetáculo. Rio de Janeiro: Contraponto.

Freud, S. (1974). Mal-estar na civilização. In: J. Strachey (Ed. e Trad.). Edição Standard das Obras Psicológicas Completas de Sigmund Freud (Vol. 21, pp. 75-171). Rio de Janeiro: Imago. (Obra Original publicada em 1929).
Freud, S. (1994a). Além do princípio do prazer. In J. Strachey (Ed. e Trad.). Edição Standard das Obras Psicológicas Completas de Sigmund Freud (Vol. 18, pp. 17-90). Rio de Janeiro: Imago. (Obra Original publicada em 1920).

Freud, S. (1994b). Luto e Melancolia. In J. Strachey (Ed. e Trad.). Edição Standard das Obras Psicológicas Completas de Sigmund Freud (Vol. 14, pp. 275-296). Rio de Janeiro: Imago. (Obra Original publicada em 1917).

Garcia, C. A., \& Coutinho, L. G. (2004). Os novos rumos do individualismo e o desamparo do sujeito contemporâneo. Psychêe, 8(13), 125-140.

Gay, P. (1989). Freud: uma vida para nosso tempo. São Paulo: Companhia das Letras. (Obra Original publicada em 1923).

Harvey, D. (2004). Condição Pós-moderna. (13a ed.). São Paulo: Loyola.

Kalina, E., \& Kovadloff, S. (1983). As cerimônias da destruição. Rio de Janeiro: Francisco Alves.

Lasch, C. (1990). O mínimo eu: sobrevivência psíquica em tempos difíceis. (5a ed.). São Paulo: Brasiliense.

Lourenço, L C. d'Avila. (2004). Reflexões sobre a violência e o homem contemporâneo. Psicologia: Ciência e Profissão, 24(1), 64-73.

Macedo, M. M. K. (2003). Uma leitura psicanalítica sobre o sofrimento na pós-modernidade. In: P. A. Guareschi, A. Pizzinatto, L. L. Krüger, \& M. M. K. Macedo (Orgs.). Psicologia em questão: Reflexões sobre a contemporaneidade. (pp. 163-175). Porto Alegre: EDIPUCRS.

Santos, B. de S. (2001). Pela mão de Alice: 0 social e o político na pós-modernidade. (8a ed.). São Paulo: Cortez.

Saraiva, J. E. M. (2002). Prazer do consumo ou consumo do prazer? AIDS, consumismo e malestar contemporâneo. Revista Mal-estar e Subjetividade, 2(1), 129-140.

Shneidman, E. S. (1993). Suicide as psychache. The Journal of Nervous and Mental Disease, 181(3), 145-147.

Shneidman, E. S. (1994). Definition of suicide. New Jersey: Aronson. 
Shneidman, E. S. (1998). Further reflections on suicide and psychache. Suicide and Life-Threatening Behavior, 28(3), 245-250.

Shneidman, E. S. (1999). The psychological pain assessment scale. Suicide and Life-Threatening Behavior, 29(4), 287-294.

Shneidman, E. S. (2004). Autopsy of a suicidal mind. New York: Oxford University.

Shneidman, E. S. (2005). How I Read. Suicide and Life-Threatening Behavior, 35(2), 117-120.
Sisto, N. (2003). Ventana a la violencia. Montevideo: Matices.

Souza, R. T. de (2000). Sentido e alteridade: Dez ensaios sobre o pensamento de Emmanuel Levinas. Porto Alegre: EDIPUCRS.

Vilhena, J. de, \& Maia, M. V. C. M. (2002). Agressividade e violência: reflexões acerca do comportamento anti-social e sua inscrição na cultura contemporânea. Revista Mal-estar e subjetividade, 2(2), 27-58. 